\title{
Inclusive Education: Identifying Teachers' Perceived Stressors in Inclusive Classrooms
}

\author{
Darlene Brackenreed \\ Nipissing University
}

\begin{abstract}
This research replicates the study conducted by Forlin (2001) in Churchlands, Western Australia. Forlin's Inclusive Education Teacher Stress and Coping Questionnaire was adapted from the original questionnaire to more accurately reflect the language and practice of inclusion in Ontario (Frost \& Brackenreed, 2004). The purpose of this study was to determine teachers 'perceptions of their levels of stress with respect to teaching students with an identified exceptionality in their inclusive classrooms, as well as to compare the perceptions of stress in the two populations. A final outcome of the study was to inform practice for teachers of Ontario and perhaps other regions of Canada. The population for this study was drawn from teachers in northeastern Ontario, Canada. Implications for teachers and recommendations for further research are presented.
\end{abstract}

In Canada, unlike the United States for example, there is no federal department of education legislating educational policies for the provinces and territories. The curriculum, financing, and delivery of education services, including special education services, are governed by provincial and territorial legislative assemblies and may differ among jurisdictions (Winzer, 1999). Federal legislation and the courts govern laws pertaining to rights and individual freedoms, and the provincial ministries of education must set policies in accordance with the laws. In each jurisdiction there are elected school boards that must adhere to the education acts, regulations, and direction of the Ministry of Education.

The Canadian Charter of Rights and Freedoms, passed in 1982, entrenches the rights of all citizens to receive equal treatment under the law. This includes non-discrimination against persons with impairments, disabilities, and handicapping conditions. Each Ministry of Education must adhere to the tenets within the Charter and have compulsory education laws that allow the inclusion of students with special needs, to ensure that all students receive a free and appropriate education. 
Across Canada, services in special education share many common features, such as the inclusion of students with special needs in regular classrooms, known as inclusion. In Ontario, beginning in the $1970 \mathrm{~s}$, the province began to consider mandatory inclusion of students with exceptionalities into regular classrooms. Amendments to the Education Act (Ontario Education Amendment more commonly referred to as Bill 82; Ontario Provincial Government, 1980) brought into place mandatory requirements for school boards to offer special education programs and services. Recognizing that some jurisdictions in the province did not require full special education programs, the Ontario government designed this bill to be non-regulatory pertaining to placement of students. This allowed for final placement decisions to be made by the individual school boards and allowed these boards to purchase services from outside agencies and other boards (Weber \& Bennett, 1999).

At first, most students with exceptionalities were placed in self-contained classrooms within their local school boards, grouped according to their specific needs. By 1991, integration was the preferred placement for any student regardless of their individualized need (Weber \& Bennett, 1999). Today, most teachers in Ontario have to accept the fact that there will be students with exceptionalities in the regular classroom. Leithwood (2006) explained the consequences of this significant change to the life of teachers in Ontario:

Stress is not only an unavoidable by-product of significant change, it is an essential condition leading to constructive change as long as it is in manageable doses. But turbulence and stress have been considerably exaggerated over the past two years in Ontario as a consequence of the speed with which policy changes have been introduced, and because of the painful consequences for teachers, administrators, trustees, students, and others of the content of many of those changes (para. 4).

According to the Ontario College of Teachers, in 2004 there was an attrition rate of $30 \%$ during the first five years for all new teachers (Ontario College of Teachers, 2004). In 2004, $9.5 \%$ to $10 \%$ of the entire full-time teaching profession turned over annually (Ontario College of Teachers, 2004). The most common reason cited for leaving was lack of support to adjust to the demands of the classroom. The Canadian Teachers' Federation June 2001 Workplace Survey found that $47 \%$ of teachers quit before retirement due to stress and frustration. While it may be argued that there are many sources of discontent for the teachers during this time, such as educational reforms based on market-driven and economic accountability, rather than based on social justice, these reforms also impacted the education of students with special needs and their teachers.

Amongst the stressors described by teachers is the practice of inclusion in the education of students with special needs (Burke, Greenglass, \& Schwarzer, 1996; Farber, 1991; Hastings \& Bham, 2003; Hayes, 2005; Singer, 2006; Vandenberghe \& Huberman, 1999). The most stressful were those perceived as interfering with a teacher's instruction time, including ever-increasing amounts of paperwork, extracurricular demands, and interpersonal conflicts. Other stressors identified included workload, time management, lack of general support, and insufficient teacher preparation.

Similar to Canada, the individual states and territories in Australia are responsible for their own educational systems. Each jurisdiction has its own Education Act and establishes its own regulations and policies regarding the education of students with special needs. There are many similarities between the content of these Acts, but the educational practices for students with special education needs differ due to the independent decision making within each agency. 
A more inclusive approach to education in Australia began in the early 1970s with the introduction of the normalization principle. The greatest amount of change has occurred since the Salamanca Statement (United Nations Educational, Scientific and Cultural Organization, 1994). By the end of 1981, every jurisdiction in Australia had a policy on students with disabilities, and inclusion was slowly beginning to become a reality in schools (Carroll, Forlin, \& Jobling, 2003). In 1994, the de Lemos Report identified approximately 62,000 children (i.e., about $2 \%$ of the total population) in 1992 with disabilities in Australia. Of these, 27\% were attending special schools, $24 \%$ were in special education classes, and $49 \%$ were in regular schools. Most regions now have a commitment to improving educational outcomes and inclusive education as the preferred service delivery model (Gavrielatos, 2006; Meyer, 2001; Senate Employment, Education and Training Reference Committee, 2002). In addition, the Australian government announced at the end of 2004 its intention to proceed with the Disability Standards for Education (2004) under the Disability Discrimination Act of 1992. The standards were designed to make clear the legal obligations of authorities in relation to enrolment, participation, curriculum development and delivery, student support services, and elimination of harassment and victimization for children with disabilities.

In Australia, Forlin (2001) reported that $89 \%$ of the teachers surveyed perceived they had received inadequate pre-service training for teaching students with exceptionalities. The recent non-mandated change in Australia to include students with special needs in regular classrooms has impacted on the perceived level of stress experienced by teachers, as reported by Forlin, namely insufficient in-school support, low perceptions of professional competency, and student behaviours.

Bunch, Lupart, and Brown (1997) examined Canadian educators' attitudes about the inclusion of students with exceptionalities. They found that teachers were generally supportive of the philosophy of inclusion as it was directly related to issues of equity and rights; it provided opportunities to reveal learning potential and it possessed general benefits for all students. Conversely, teachers expressed concerns regarding its effects on regular classroom teachers, specifically adequacy of teacher preparation and issues of teacher workload. They also expressed concerns about adequate supports for the inclusive classroom. Among the desirable supports identified in the study were adequate time for planning, support personnel, manageable class sizes and composition, classroom resources, sufficient training, and mentorship and leadership from school administration.

Avramidis and Norwich (2002), in their review of the Canadian literature with respect to teachers' attitudes toward inclusion, concluded that while teachers are positive toward the general philosophy of inclusion, they do not adopt a "total inclusion" approach to special education. They appear to be more willing to include students with mild disabilities and physical or sensory impairments than those students with more complex needs. Additionally, Avramidis and Norwich noted that, with resources and support, teachers' attitudes could become more positive. However, the researchers did not uncover any studies that showed the move toward more positive attitudes to inclusion leading to widespread acceptance of full inclusion. Teachers believed that when additional supports to moderate the effect of change were in place, inclusion was feasible. The majority of teachers in the studies reviewed did not believe these supports were in place or imminent. Canadian educators appear to recognize the benefits of the inclusive approach, but cite clearly stated concerns: the need for appropriate pre-service and in-service teacher preparation, logistical and personal support from administrators, and an appropriate and reasonable workload. 


\section{Purpose of Study}

With financial assistance from Nipissing University, we investigated the perceptions of teachers in northeastern Ontario regarding the inclusion of students with special needs in a regular classroom setting and whether inclusion places stressors on the classroom teacher. The purpose was to identify items perceived as the most stressful and make comparisons between the perceptions of stress by teachers in the Australian and Canadian studies. The final outcome was to determine what teachers expressed as necessary in order for them to deem inclusion as viable and successful.

\section{Methodology}

\section{Population and Sample}

The population in this study was teachers in northeastern Ontario teaching students with exceptionalities in the regular classroom from four English public school boards and four English Catholic school boards. From this population of approximately 4175 elementary and secondary school teachers, a sample of 269 teachers responded to the mailed, self-administered questionnaire. It is not possible to calculate a reliable response rate because it is not known how many of these teachers had students with special needs in their classroom. We do know that the percentage of students receiving support for special education needs varied from a low of $9 \%$ to a high of $23 \%$ during the time of the study. Respondents indicated that they held a mean of 13 years of teaching experience.

\section{Measure}

This research is a replication of the study conducted by Forlin (2001) in Churchlands, Western Australia. The Inclusive Education Teacher Stress and Coping Questionnaire was adapted from the original questionnaire to more accurately reflect the language and practice of inclusion in Ontario (Frost \& Brackenreed, 2004). The Teacher Stress and Coping Questionnaire (TSC) ${ }^{1}$ is comprised of four parts. Part A solicits information about students in the classroom who have been identified by an Identification Placement Review Committee (IPRC) ${ }^{2}$, for those who are waiting to be identified by an IPRC, or who are considered to be "at risk." Part B requests information about potential stressors associated with inclusive education and Part $\mathrm{C}$ consists of a variety of coping strategies that might be employed by the teacher. Part D is concerned with general information on external variables such as demographic details of the school and personal teaching data. Each section offers the respondent an opportunity to offer comments in an open-ended question. The scale showed acceptable internal consistency (Cronbach's $\alpha=$ $.91)$.

Potential stressors are divided into seven sub-sections on the questionnaire: administrative issues, support, student behaviour, the classroom, parents, professional competency, and personal competency. Seventy-five items using Likert-type scale responses were used to measure the extent of their perceived stressfulness to each teacher. The second half of the questionnaire measured coping strategies and the perceived effectiveness of each strategy for teachers. A Li-

\footnotetext{
${ }^{1}$ Measure can be obtained by contacting the author.

${ }^{2}$ In Ontario, the IPRC makes identification and placement decisions for students with special needs.
} 
kert-type scale technique presented a set of statements to which respondents were asked to press agreement or disagreement on a 5-point scale. Each degree of agreement was given a numerical value from $1=$ does not apply to 5, indicating a high level of agreement with the statement. An open-ended question at the end of each sub-section of the questionnaire asked for any comments that the respondent wished to add.

\section{Analysis of the Data}

Descriptive statistics, including measures of central tendency and variability, were used to profile the sample of teachers. Open-ended questions were analyzed according to themes and related to the quantitative findings.

The responses varied substantially according to whether the stressor applied to the particular respondent because the questionnaire contained covert data. To ensure that a maximum number of responses were employed in the analysis, data were re-coded to combine responses recorded as Not stressful with responses coded as Does not apply so that the scale changed to 1 being low and 4 being high. Respondents' factor scores were determined by computing the mean level of stress across all items included in the respective factors. Higher scores are associated with higher levels of stress. Due to the limited number of responses to questions regarding stress related to health, safety, and hygiene, the category was omitted from further analysis.

The experience of stress is not discrete: People experience different and varying degrees of stress. As such, our model proposed that the Likert-style scale employed accesses intervaltype responses which assumed to be effectively equal in degree of change (Beals \& Krantz, 1993; Jöreskog \& Moustaki, 2001). Thus, this model relies upon the assumption that stress is not ordinal in nature but continuous and our scale reflects this. Each response variable represents individual perceptions of stress, which through exploratory factor analysis (EFA) can expose the underlying latent factors that contribute to the experience of stress. Given that the response variables are measured using a Likert-style scale, they are discrete scores and not continuous so that the EFA is employed here primarily as a means of data description and reduction. Where EFAs are used for these purposes, many of the primary assumptions regarding the data distribution need not be met (Tabachnick \& Fidell, 2007).

Calculating correlation coefficients between individual items and the mean factor score assessed internal reliability. All items that produced coefficients below .50 were removed from the analysis. Commonalities in the responses were identified using Principal Component Analysis and a Varimax rotation. Using the analysis, factors were extracted. This was followed with the Kaiser-Meyer-Olkin Measure of Sampling Adequacy, an Oblique rotation to determine that factor analysis could be performed.

Responses to the open-ended questions were recorded, categorized, and organized according to the findings of the questionnaire, and the data generated through the open-ended items were examined to see how they contributed to the understanding of the questionnaire findings. Through this logical process, the responses to the questionnaire are reported with confidence.

\section{Findings}

This article reports the findings of Part B of the Teacher Stress and Coping Questionnaire (TSC) pertaining to potential stressors for teachers in inclusive classrooms. Teachers were asked to respond to the degree to which they perceived different issues as stressful. Table 1 illus- 
trates the perceived severity of student need and control over placement of the child in the classroom. Tables 2 and 3 show the steps in creating a pattern matrix. To ensure that the understandings of teachers' perceptions were not limited to the findings of the questionnaire items, teachers were given an opportunity to respond to an open-ended question. These comments are reported according to the organization and categories of the findings of the questionnaire.

Teachers were asked to rate the severity of their students' special needs and indicate their perception of control over having the children placed in their classroom. The teachers indicated that they perceived the exceptional students in their classroom to have severe needs and that they had to accept the situation as they had little control over the placement of the children into their classroom (see Table 1). This creates a stressful situation for teachers. Sandler and Lakey (2002) describe the locus of control for an individual as a moderator of stress. In other words, if the individual perceives herself/himself to have control over a situation, s/he is less likely to experience higher levels of stress. As one teacher said, "More and more responsibility and stress has been put onto the teachers' shoulders the last few years." Another commented, "My classroom is usually a relaxed, active, and happy place and only my family and my doctor are aware of the effects of stress on my physical and mental health." A respondent in the study succinctly summed up the situation when she wrote, "I am experiencing very high stress and thinking about leaving the teaching profession." The stress levels among teachers are going through the roofespecially in Ontario!

Table 1

Severity of Student Need and Control Over Placement of Child in Classroom

\begin{tabular}{lrr}
\hline & Frequency & Valid percent \\
\hline $\begin{array}{lr}\text { Severity of student need } \\
\text { Valid }\end{array}$ & & \\
Mild & 4 & 4.1 \\
Moderate & 40 & 40.8 \\
Severe & 54 & 55.1 \\
Total & 98 & 100.0 \\
Missing & & \\
No response & 2 & 2.0 \\
Total & 100 & 100.0 \\
& & \\
Control over placement & & \\
Valid & & 69.4 \\
Have to accept & 68 & 11.2 \\
Usually have to accept & 11 & 14.3 \\
Neutral & 14 & 3.1 \\
Sometimes change situation & 3 & 2.0 \\
Could change situation & 2 & 100.0 \\
$\quad$ Total & 98 & \\
Missing & 2 & \\
Total & 100 & \\
& & \\
\hline
\end{tabular}




\section{Most Stressful Issues for Teachers in Inclusive Classrooms}

To obtain a suitable measure for stress, each of the categories is treated as a separate factor that addresses different types of potential stressors. The five factors identified relate to professional competency, lack of appropriate training, behaviours of the child with the disability, access to classroom supports, and parents' expectations and level of understanding of their child's exceptionality. Using Principal Component Analysis and a Varimax rotation, we determined the commonalities in the data. We defined the factors as previously introduced by Forlin (2001), increased the internal reliability as was done previously, and then investigated the possible presence and existence of any factors within the data. We discovered a 5 -factor solution that accounted for $53.95 \%$ (see Table 2) of the total variance: lack of appropriate training for teachers and professional competency, student behaviours, access to support services, and parents.

All values were moderate with a minimum of .60 . Stress was identified as the common element. Using the analysis, five factors were extracted with Eigenvalues of 14.76, 6.26, 4.27, 2.99 , and 2.49. This was confirmed with an Oblique rotation for five factors. The Kaiser-MeyerOlkin Measure of Sampling Adequacy was sufficiently high at .75, $p=.01$ to perform factor analysis. The five factors were confirmed by re-running the extraction with the same Eigenvalues. A pattern matrix using maximum likelihood and Oblimin rotation with Kaiser normalization illustrated the factors.

The factor correlation matrix revealed moderately strong positive relationships between professional competency and lack of appropriate training (.15), the behaviour of the child (.30), and access to classroom supports (.26). Lack of appropriate training correlated positively with the behaviour of the child (.24) and access to classroom supports (.19). The behaviour of the child correlated positively with access to classroom supports (.17). The parent factor did not in any instance show a positive correlation, indicating that teachers do not perceive there to be a relationship between parents and the other four factors.

Of the 36 items identified as stressful for teachers $(M=2.56, S D=1.25), 8$ were reported to be the most stressful with a mean of $3.26, S D=1.02$. The items are closely associated with individual teachers' perceptions about self-competency and the behaviours of the child.

Eighty-three percent of teachers reported that they feel their ability to teach other students as effectively as they would like is impaired by the presence of a child with an exceptionality in the classroom and that it is stressful for them $(M=3.76, S D=1.23)$. One of the respondents wrote,

I worry about the other so-called 'average and bright' children. They deserve and have a right to my time but sometimes they have to wait or rely on one another. They are the ones the government wants to test and I have to make sure they learn the curriculum.

Eighty-five percent of the teachers in the sample expressed concern with the need to provide an appropriate educational program for the child $(M=3.55, S D=1.08)$ by adjusting unit plans and planning a child's IEP. In the open-ended question, a teacher responded, "I love teaching but feel that accommodating and modifying for special needs children can be extremely draining. I feel my health has been affected." 
Table 2

Principal Component Analysis

\begin{tabular}{|c|c|}
\hline Item & Extraction \\
\hline Record keeping & .67 \\
\hline Planning child's IEP & .69 \\
\hline Adjusting unit plans & .69 \\
\hline Obtaining funding & .71 \\
\hline Taking full responsibility for child's welfare & .60 \\
\hline Accountable for child's educational outcomes & .78 \\
\hline Coordination of support personnel & .66 \\
\hline Change of routine at short notice & .70 \\
\hline Age appropriate resources for ability level & .69 \\
\hline Accessing occupational therapy & .76 \\
\hline Accessing physiotherapy & .81 \\
\hline Accessing speech therapy & .83 \\
\hline Allocation of resource teacher & .75 \\
\hline Allocation of speech and language & .82 \\
\hline Allocation of teacher aide time & .66 \\
\hline Employing a teacher aide & .75 \\
\hline Replacement aide during sick leave & .64 \\
\hline Inappropriate social skills & .71 \\
\hline Severity of special needs of child & .77 \\
\hline Attention seeking & .76 \\
\hline Hyperactive & .82 \\
\hline Dominates classmates & .73 \\
\hline Manipulative & .72 \\
\hline Unaware of danger & .77 \\
\hline Disturbs others & .76 \\
\hline Throws tantrums & .73 \\
\hline Physically attacks others & .81 \\
\hline Verbally rude to others & .81 \\
\hline Unpredictable reactions & .80 \\
\hline Runs away & .77 \\
\hline Behaviour problems on playground & .76 \\
\hline Child's interpersonal relationships & .71 \\
\hline Management of sexual behaviours with peers & .64 \\
\hline Time available for other students & .78 \\
\hline Monitoring other students & .78 \\
\hline Class disrupted by child & .77 \\
\hline Excessive parent meetings & .71 \\
\hline Parent not understanding child's capabilities & .80 \\
\hline Parent not understanding long term prognosis & .84 \\
\hline Parent not coming to terms with disability & .76 \\
\hline Parent / teacher tension & .67 \\
\hline Socio-economic disadvantage of family & .61 \\
\hline Insufficient pre-service education & .80 \\
\hline Inadequate in-service re: child's condition & .90 \\
\hline Inadequate in-service re: meeting needs of child & .80 \\
\hline
\end{tabular}


Teachers' Perceptions of Stress in Inclusive Classrooms

Table 3

Pattern matrix

\begin{tabular}{|c|c|c|c|c|c|}
\hline \multirow[t]{2}{*}{ Item } & \multicolumn{5}{|c|}{ Factor } \\
\hline & 1 & 2 & 3 & 4 & 5 \\
\hline Inadequate in-service for child's need & & 1.06 & & & \\
\hline Insufficient in-service educational needs & .81 & & & & \\
\hline Insufficient pre-service education & .81 & & & & \\
\hline Change of routine at short notice & .36 & & & & \\
\hline Replacement aide during sick leave & & & & & \\
\hline Verbally rude & & .86 & & & \\
\hline Unpredictable reactions & & .83 & & & \\
\hline Problems on playground & & .82 & & & \\
\hline Dominates classmates & & .80 & & & \\
\hline Hyperactivity & & .79 & & & \\
\hline Throws tantrums & & .78 & & & \\
\hline Physically attacks others & & .77 & & & \\
\hline Attention seeking & & .74 & & & \\
\hline Class disrupted by child & & .73 & & & \\
\hline Disturbs others & & .73 & & & \\
\hline Manipulative & & .71 & & & \\
\hline Inappropriate social skills & & .70 & & & \\
\hline Runs away & & .67 & & & \\
\hline Maintaining safety of others & & .65 & & & \\
\hline Unaware of danger & & .53 & & & \\
\hline Managing interpersonal relationships & & .49 & .32 & & \\
\hline Maintaining child's safety & & .46 & & & \\
\hline Management of sexual behaviours with peers & & .43 & & & \\
\hline Excessive parent meetings & & .42 & & & \\
\hline Severity of special needs of child & & .40 & & & \\
\hline Age appropriate resources for ability level & & -.38 & & & \\
\hline Responding to child's personality & & .37 & & & \\
\hline Reduced ability to teach others & & & .82 & & \\
\hline Monitoring other students & & & .76 & & \\
\hline Time available for others & & & .71 & & \\
\hline Accountable for child's educational outcomes & & & .65 & & \\
\hline Meeting child's needs & & & .63 & & \\
\hline Adjusting unit plans & & & .61 & & \\
\hline Sustaining active learning environment & & & .51 & & \\
\hline Taking full responsibility for child's welfare & & & .42 & & \\
\hline Allocation of resource teacher & & & .39 & & \\
\hline Preparing child's IEP & & & .31 & & \\
\hline Accessing speech therapy & & & & .87 & \\
\hline Allocation of speech and language & & & & .80 & \\
\hline Accessing physiotherapy & & & & .80 & \\
\hline Accessing occupational therapy & & & & .76 & \\
\hline Allocation of teacher aide time & & & & .45 & \\
\hline Employing a teacher aide & & & & .37 & \\
\hline Undertaking tasks associated with child's condition & & & & .35 & \\
\hline Coordination of support personnel & & & & .34 & \\
\hline Parent not understanding long term prognosis & & & & & -.87 \\
\hline Parent not understanding child's capabilities & & & & & -.83 \\
\hline Parent unwilling to come to terms with disability & & & & & -.65 \\
\hline Socio-economic disadvantage of family & & & & & -.41 \\
\hline Meeting parent expectations & & & & & -.38 \\
\hline Empathizing with parent & & & & & -.36 \\
\hline Parent/teacher tension & & & & -.36 & \\
\hline Confusing laziness with inability & & & & & -.33 \\
\hline Determining how much to challenge child & & & .32 & & \\
\hline
\end{tabular}


Related to the issue of teacher competency is the perceived lack of appropriate training to meet the exceptional needs of a child. The majority of teachers believed that their lack of preparation prior to entering the classroom was stressful: $58 \%$ indicated they had received inadequate pre-service training $(M=2.59, S D=1.23), 62 \%$ reported in-service training to be inadequate concerning the child's specific exceptionality $(M=2.81, S D=1.57)$, and $63 \%$ thought inservicing with respect to meeting the needs of the child was insufficient $(M=2.84, S D=1.14)$. A novice teacher wrote,

Being a first-year teacher with a multi-grade classroom and two IPRC and 3 IEP students, I found it disheartening and frustrating at times. I went to teacher's college and thought I learned many things. I was still not yet ready for what my classroom would bring.

In seeking out people to assist with programming, teachers demonstrated not only a lack of time but also a lack of skill: "With such a heavy curriculum load it's hard to find materials and people to help with how to adapt/modify/accommodate the expectations or to find a program to assist in the child's growth."

Another area of concern for teachers was with the behaviours of the child with the exceptionality. Over $75 \%$ of teachers reported that the child disturbed others in the class $(M=3.52, S D$ $=1.36)$, while $70 \%$ stated that the child disrupted whole class teaching $(M=3.38, S D=1.45)$. Perhaps this results from short attention span as reported by $92 \%$ of the respondents $(M=3.79$, $S D=.98)$ or from inappropriate social skills $(M=3.66, S D=1.20)$. Additionally, $80 \%$ of teachers reported that the management of the child's interpersonal relationships was a source of concern $(M=3.26, S D=1.02)$. On the topic of behaviour, a respondent wrote,

Behavioural students present an extremely difficult challenge for teachers and their students. Very often these children threaten the safety of the teacher, EA, and most concerning, the safety of other students. Also, the behaviour of these children can be transferred to other students.

The most disconcerting comment was one concerning lack of social skills:

This child does not model, therefore she is not learning from others. She does not interact at all with her classmates. When she first came to us, she pulled down her pants and went to the bathroom in the schoolyard.

With respect to teachers' perceptions of support in the classroom, securing ageappropriate educational resources for the child's ability level was identified as a source of stress $(M=3.03, S D=1.11)$. Coordination of support personnel $(M=2.87, S D=1.26)$; a change of routine at short notice, such as a teaching assistant absent $(M=2.96, S D=1.49)$; taking full responsibility for child's welfare $(M=3.05, S D=1.27)$; and being held accountable for child's educational outcomes $(M=3.79, S D=.98)$ all speak to issues of lack of support for the classroom teacher. Difficulty monitoring others when attending to child $(M=3.69, S D=1.18)$, whole class teaching disrupted by child $(M=3.38, S D=1.45)$, and making time available for other students $(M=3.54, S D=1.17)$ also were sources of stress for teachers, partially resulting from insufficient daily support for teachers in inclusive classrooms. One teacher summarized the voices of many when she wrote,

In the last twenty years, the severity and range of special needs has increased dramatically. Personally, I feel that most of these children were very manageable in the regular classroom if support 
in the form of an EA was provided. However, from 1995 to the present, the Ontario provincial government has taken billions of dollars out of education. The result has been that many special needs students are in classrooms and there is inadequate support available to them. The impact of this situation on classroom teachers is profoundly stressful. Teachers are coping with a completely intolerable situation.

Teachers discussed support in terms of personnel, materials, and workload: "We need more resources. Nearly half of my class has been IPRC' $d$ [identified] and I'm still waiting for a couple more. I can hardly wait to retire." "Too many impractical expectations," complained another teacher. "Only one teacher expected to be too many people at once." Finally, several teachers commented that there are children who benefit from being integrated into a regular classroom while others would learn more if they were in a more structured special education classroom with their own EA and education plan.

The demands of students with special needs were described as "staggering" by many teachers. Despite this, many of the respondents indicated that "most special needs students benefit from mainstream inclusion but more concrete support is necessary."

Teachers indicated that often they would learn just as school was starting whether or not the funding would be there to pay for EA salaries and materials. If the money was not available, any previous planning based on the availability of supports had to be shelved and the teacher was left to cope alone. Conversely, a respondent noted, "With the support I receive I do not find having this child in my room any more stressful than with any child who struggles with behaviour or learning. An excellent teaching assistant and supportive parents has made the difference."

Respondents mentioned that parents could be a source of stress: $61 \%$ and $59 \%$, respectively, believed that a parent's lack of understanding of a child's capabilities or long term prognosis caused stress $(M=2.80, S D=1.33$ and $M=2.82, S D=1.30)$. Meeting the parents' expectations was reported by $66 \%$ of respondents as being stressful $(M=3.01, S D=1.12)$. A teacher explained, "I also find that dealing with parents is usually more stressful than anything I do with the students."

\section{Least Stressful Issues for Teachers in Inclusive Classrooms}

It is interesting to note that four of the low stress issues, as perceived by the respondents, were related to teachers' interactions with the child's parents. The issue of parent-teacher tension was reported by a relatively low $37 \%$ of teachers $(M=2.08, S D=1.23)$. Seventy-two percent of teachers in the study did not feel that there were excessive meetings with parents $(M=2.05, S D$ $=1.20)$ and $82 \%$ did not experience stress by the presence of parents in the classroom $(M=1.68$, $S D=1.10)$. Empathizing with the parent also was not a stressful undertaking for $67 \%$ of the respondents $(\mathrm{M}=2.18, S D=.87)$.

Of the remaining 15 items that elicited low perceptions of stress, 7 relate to physical or speech and language exceptionalities and the special services to which the students are entitled. Eighty-six percent reported low levels of stress for obtaining physical adaptations $(M=1.39, S D$ $=.90)$; accessing physiotherapy $(M=1.52, S D=1.06)$; and undertaking tasks associated with the child's condition, such as toileting $(M=1.37, S D=.86)$. Children who have low mobility $(M=$ $1.73, S D=1.12$ ) do not appear to cause teachers undue concern nor do children with limited speech ability $(M=2.14, S D=1.46)$. Teachers routinely are not required to provide direct services for these children as teaching assistants are employed to undertake these tasks. In-school 
support in the form of employing a teacher assistant $(M=2.02, S D=1.38)$ or finding a replacement for absences $(M=1.92, S D=1.37)$ was not reported as stressful. Generally, the responsibility for securing teaching assistants or ensuring that there are substitutes in the school falls under the realm of the principal.

Within the domain of mental health, $89 \%$ of teachers indicated little concern with students acting in an over-loving manner $(M=1.45, S D=.79)$ or acting withdrawn $(M=1.84, S D=$ 1.18). In terms of managing peers' responses to health or hygiene issues, $72 \%$ suggested a low stress response $(M=1.77, S D=1.07)$, while $81 \%$ believed the management of sexual behaviours with peers was not stressful $(M=1.60, S D=1.03)$. These findings are in accordance with the study by Brackenreed, Common, Frost, Barber, and Richardson (2006) that indicated that most teachers are not aware of the characteristics and behaviours of students with mental health concerns.

\section{Discussion of the Results}

As mentioned, the five factors in the current study as compared to the Forlin study differ slightly. This allowed us to propose an understanding of the topic within a different population in different contexts. The most stressful items common to the two studies were self-perceptions of teacher competency and student behaviours. In both contexts the teachers' perceptions of adequate training and self-competency were described as insufficient, causing stress for teachers in dealing with both students with special needs and others in inclusive classrooms. Student behaviours, such as disturbing others, were cited in both studies as causing teachers stress.

The teachers in this study identified parents as a source of high stress when it came to a lack of understanding of their child's capabilities or long-term prognosis, confusing laziness with inability, or in meeting the parents' expectations; this was not a feature in the Australian context. It may be due to education and experience that the Canadian teachers have developed insights into the life of a child with special education needs and no longer have the tendency to see these students as incapable or lazy. The least stressful concerns common to both groups of teachers were parents in the classroom, parent/teacher tension, empathizing with the parent, or parent meetings. Certainly, both groups of teachers have a general understanding that parents hold high stakes in the education of their children and that historically, parents have fought hard for appropriate services and programs for their children.

Student access to special services is described in this study as a potentially low stressor for teachers, while this was not a significant outcome of the Forlin study. This may be attributed to the rights of the child to an appropriate education being entrenched through the Education Act, the Ontarians with Disabilities Act, and the Charter of Rights and Freedoms. Essentially, school boards in Ontario are required to purchase special services for students who are identified as exceptional if they do not have a professional on staff to deliver the service.

The perceptions of stress by teachers in Ontario differed from the Australian study in that providing an appropriate program for the child and being responsible for an active learning environment was not reported as significant sources of stress. This may be due in part to the preparation pre-service and in-service teachers experience related to programming and creating learning environments as opposed to teacher preparation for meeting the special education needs of individual students. Teaching experience also may have an impact on their perceptions of teacher training. The teachers in the studies had a mean of 13 and 14 years of experience in Canada and Australia, respectively, while inclusion is a relatively new model of education. 
This speaks to the issue of in-service opportunities for teachers. The formalized and controlled Professional Learning Program unilaterally imposed by the past government was not respectful of teachers and was exceedingly prescriptive. It created a unique professional jeopardy by tying a set of courses to the revoking of the licence to teach. This is particularly important, recognizing that development is not just acquiring knowledge or teaching skills, but sustaining motivation and innovation as well. There are strong indications of the need for additional support for teachers. The loss rate of new teachers is high, with about one-third in the first five years exiting the profession. The strains upon teaching are also manifested in disability leaves, which have doubled since 1991, and depression rates, in particular, which have been identified as onethird higher than in other professions (Ontario Ministry of Education, 2004).

With most school boards opting for decentralization of administration, schools are now given the opportunity to select and design their own professional development in an attempt to more closely meet the needs of the school staff. The responsibility for the organization of professional development lies with the school principal. With the teachers in this study demonstrating dissatisfaction with the in-service training they were receiving regarding meeting the individual needs of students with special education needs, closer inspection of the opportunities being provided needs to take place.

As the teachers in this study noted, inclusion is not perceived as a significant source of stress when the appropriate supports are in place. The decrease in the educational budget by the Harris government in the $1990 \mathrm{~s}$, in combination with the increased demands placed on teachers, such as inclusion and a mandate for greater teacher accountability through standards-based tests based on a new curriculum, has created a range of abilities in the classroom that many argue are too great for one teacher. Teachers are struggling to meet the needs of all learners in the regular classroom, and they are voicing their concerns on behalf of their students, as well as themselves. As advocates for supports to inclusive education, teachers tend to view themselves as opponents rather than team members (Bennett, Deluca, \& Burns, 1997), creating another source of stress resulting from the perceived lack of support to the educational reform strategy of inclusion.

Some researchers view inclusion as a policy driven by an unrealistic expectation that money will be saved. Furthermore, they argue that trying to force all students into the inclusion mould is just as coercive and discriminatory as trying to force all students into the mould of a special education class or residential institution (Huston, 2007). The Council for Exceptional Children (1993) advocates for a continuum of services to be offered to students with special education needs and expresses concern regarding mandated full inclusion.

In spite of the differences in context, the perceptions of the Australian and Canadian teachers regarding inclusion are remarkably similar. In both studies, the teachers support the basic philosophy of inclusion but feel they have been left to their own devices to survive the stresses created by including all students in the regular classroom without appropriate supports. In previous times, students with special education needs were sent to institutions where their education became the responsibility of the people who worked within these environments. Now they are sent to schools where teachers struggle with how to create the least restrictive environment for all students while being held to one choice of placement. The sense of belonging and ownership inherent in the philosophy of education has yet to be experienced by many of the teachers in these studies.

The challenges of teaching are many. Teaching students today is very different than in previous generations. For example, there are much higher expectations by students, families, and society and students need to know more now than ever before to succeed. Yet, students are also 
less in awe of authority than in previous generations. The increase in children's antisocial, acting-out, and aggressive behaviour is especially challenging to schools. Like never before, there is a broader diversity of students, both culturally and in terms of how they learn. Since 1990, an average of 225,000 immigrants of all ages arrive in Canada every year of whom $60 \%$ come to Ontario (Ontario Ministry of Education, 2004). In southern Ontario, up to $10 \%$ of the school-age population have a home language other than English or French; in Toronto, this figure is over $20 \%$. Progressive integration policies mean that classes are composed of greater numbers of students with special educational needs than in the past (Ontario Ministry of Education, 2004).

A first-year teacher induction program to facilitate collaboration between faculties of education and school systems and mentoring of new teachers by experienced educators have been proposed by the Ministry to address the issue of teacher preparation (Ontario Ministry of Education, 2004). In this study, educators with over 10 years of teaching practice indicated that they are experiencing stress with respect to meeting the needs of special education students, suggesting that they need professional development and that their mentoring of novice teachers in this domain may not be effective.

The most disquieting outcome of this study may be the fact that despite our history and legislation pertaining to inclusion in Ontario, many teachers continue to experience high levels of stress resulting from the inclusion of students with special education needs in regular classrooms. Inadequate preparation in pre-service and in-service programs causing low perceptions of teacher self-competency; understanding and management of student behaviours; insufficient daily support in the classroom; and meeting the expectations of others, such as parents, continue to be sources of concern for teachers.

Further research to address the issues must be undertaken in order to preserve the integrity of the inclusion movement while supporting the students, families, and teachers. Teachers are asking for help, demonstrated in part by the relatively escalated attrition rate and through the results of studies such as this one. It is imperative that policy makers take heed to the voices of teachers and put measures in place to address their concerns. A Grade 4 classroom teacher in this study summed it up by noting,

I feel classroom teachers experience a great deal of stress in dealing with students with special education needs. However, teachers are dedicated to helping all students learn and I am confident they will continue to meet these challenges provided they are given the much needed support involved.

\section{Limitations of the Study}

Results of this study should be interpreted with caution, as bias may be present in the sample. Other information to verify and support these data, such as direct observations or interviews, was not used. By design, the sample was limited to teachers in northeastern Ontario with students who have special needs in their classroom, creating a relatively small sample size, making it difficult to generalize the findings to a larger population of teachers of students with and without special needs. As such, the sample is a fixed group sample, not a random sample. While the statistical procedures employed in this study originally were not designed to be applied to fixed group samples, it was necessary to study the group of persons who had the experience

and understanding of inclusion in order for the respondents to answer the items on the 
questionnaire. This under-representation in the sample, in part induced by the voluntary participation, presents a limitation in the study.

\section{Recommendations}

The working table report, Special Education Transformation (2006), commissioned by the Ministry of Education, addresses many of the issues raised by teachers in this study. The document recommends that the Ministry of Education, through the Ontario College of Teachers, establish the completion of a half-course on special education before issuing an Ontario teaching certificate, funding for professional development related to special education based on training gaps as identified through research, standards for educational assistants, and standards for teachers of students with special needs. The document also calls for the development of resources related to special education; curriculum documents and related forms to address the needs of all students, including those with special needs; improved parent collaboration; and the creation of a multi-ministry framework that supports an integrated service delivery and funding model. To date, these recommendations have not been acted upon despite research studies and the working table report that speak for students with special education needs and their families.

If teachers are to design individual education plans to meet the unique needs of students with special needs, one question begs to be asked: How can it be possible that one setting, the regular classroom setting, can be the most appropriate setting for every one of these students? A continuum of placements, supports, and services should be made available for all students, with the assumption that every student's first consideration for placement is in regular education. All placement decisions should be based on a well-developed IEP with an emphasis on the needs of the child, her/his peers, and the reasonable provision of services. Inclusion requires that we reflect continuously on the practice of inclusion and the ensuing results for our students and teachers.

Teachers in this study clearly indicate that they are generally supportive of the philosophy of inclusive education, but also indicate that not all students thrive in this regular classroom setting, particularly with the limited supports that are currently available. One might ask where the money saved from the closure of institutions has been spent, considering the lack of supports available to the people in inclusive classrooms. The financial picture for school boards lies primarily with the provincial government, which should address the necessity of a financial transformation for students with special education needs. It would appear that teachers are caught in the crossfire as politicians weigh the public support for special education, a social justice construct, against the market-driven, economic accountability movement of the previous Ontario government. In the meantime, our children are suffering as teachers struggle to help them achieve their potential in inclusive classrooms without the supports deemed essential for success. 


\section{References}

Avramidis, E., \& Norwich, B. (2002). Teachers' attitudes towards integration / inclusion: A review of the literature. European Journal of Special Education Needs Education, 17(2), 129-147.

Beals, R., \& Krantz, D. H. (1993). The foundations of ordinal factor analysis: Affine and spherical geometries induced by a collection of weak orders. Journal of Mathematical Psychology, 37, 157199.

Bennett, T., Deluca, D., \& Burns, D. (1997). Putting inclusion into practice: Perspectives of teachers and parents. Exceptional Children, 64, 115-130.

Brackenreed, D., Common, R., Frost, L., Barber, P., \& Richardson, W. (2006). An educational response to mental health issues in the classroom. In J. A. LeClair \& L. T. Foster (Eds.), Issues in mental health: Concepts, policy and practice. Victoria, BC: Western Geographical Press.

Bunch, G., Lupart, J., \& Brown, M. (1997). Resistance and acceptance: Educator attitudes to inclusion of students with disabilities. North York, ON: York University.

Burke, R., Greenglass, E., \& Schwarzer, R. (1996). Predicting teacher burnout over time: Effects of work stress, social support, and self-doubts on burnout and its consequences. Anxiety, Stress, and Coping: An International Journal, 9(3), 261-275.

Carroll, A., Forlin, C., \& Jobling, A. (2003). The impact of teacher training in special education on the attitudes of Australian pre-service general educators towards people with disabilities. Teacher Education Quarterly, 30, 65-79.

Farber, B. (1991). Crisis in education: Stress and burnout in the American teacher. San Francisco: Jossey-Bass.

Forlin, C. (2001). Inclusion: Identifying potential stressors for regular class teachers. Educational Research, 43(3), 235-245.

Frost, L., \& Brackenreed, D. (2004). The Teacher Stress and Coping Questionnaire. Unpublished study, Nipissing University.

Gavrielatos, A. (2006).Quality education for all: Funding matters. Retrieved July 12, 2008, from http:// cpd.org.au/node/3870, paragraph 31.

Hastings, R., \& Bham, M. (2003). The Relationship between student behaviour patterns and teacher burnout. School Psychology International, 24(1), 115-127.

Hayes, C. (2005). Stress relief for teachers: The coping triangle. Bibra Lake, Australia: Routledge.

Huston, J. (2007). Special education inclusion. Retrieved July 10, 2008, from www.weac.org/ resource/speced.htm

Jöreskog, K. G., \& Moustaki, I. (2001). Factor analysis of ordinal variables: A comparison of three approaches. Multivariate Behavioral Research, 36(3), 347-387.

Leithwood, K. (2006). School leadership in times of stress. Retrieved July 12, 2008, from http:// www.oise.utoronto.ca/orbit/school_leader_sample.html

Meyer, L. (2001). The Meyer report. Victoria, BC: Department of Education, Employment and Training.

Ontario College of Teachers. (1999). Professionally speaking. Retrieved July 11, 2008, from http:// www.oct.ca/publications/professionally_speaking/september_1997/ps2car.txt

Ontario College of Teachers. (2004). Professionally speaking. Retrieved July 11, 2008, from http:// www.oct.ca/publications/professionally_speaking/june_2004/letters.asp

Ontario Ministry of Education. (2004). Retrieved July 30, 2008, from http://www.edu.gov.on.ca/ eng/ document/nr/04.03/teacherexcellence.pdf

Ontario Provincial Government. (1980). The education act on special education. Retrieved July 6, 2008, from www.edu.gov.on.ca/eng/general/elemsec/speced/edact.html

Sandler, I., \& Lakey, B. (2002). Perceived support and low emotional distress: The role of enacted support, dyad similarity, and provider personality. Personality and Social Psychology Bulletin, 28(11), 1546. 
Senate Employment, Education and Training Reference Committee (2002). Inquiry into the education of students with disabilities. Canberra: Author.

Singer, J. (2006). Stirring up justice: Writing...reclaiming time, managing stress, and creating a healthy life: How teacher thinking shapes education. Hamilton, MT: MindFlight Publishing.

Tabachnick, B. G., \& Fidell, L. S. (2007). Using multivariate statistics (5th ed.) Boston: Pearson Education, Inc.

The Council on Exceptional Children. (1993). Position paper. Virginia: Author.

United Nations Educational, Scientific and Cultural Organization. (1994). The Salamanca statement and framework for action on special needs education. Retrieved July 12, 2008, from http:// unesdoc.unesco.org/images/0009/000984/098427eo.pdf

Vandenberghe, R., \& Huberman, A. (Eds.). (1999). Undertsanding and preventing teacher burnout: A sourcebook of international research and practice. New York: Cambridge University Press.

Weber, K., \& Bennett, S. (1999). Special education in Ontario schools (4th ed.). Thornhill, ON: Highland Press.

Winzer, M. (1999). Children with exceptionalities in Canadian classrooms (5th ed.). Scarborough, ON: Allyn \& Bacon.

\section{Author's Note}

Correspondence concerning this article should be addressed to Darlene Brackenreed, Ph. D., Assistant Professor, Nipissing University, 100 College Drive, North Bay, ON, P1B 8L7.

Email: darleneb@nipissingu.ca 